\title{
Acceptance of Technologies for Aging in Place: A Conceptual Model
}

Christina Jaschinski ${ }^{1}$, PhD; Somaya Ben Allouch ${ }^{2}, \mathrm{PhD}$; Oscar Peters ${ }^{3}, \mathrm{PhD}$; Ricardo Cachucho ${ }^{4}$, PhD; Jan A G M van Dijk ${ }^{5}, \mathrm{PhD}$

\footnotetext{
${ }^{1}$ Research Group Technology, Health \& Care, Saxion University of Applied Sciences, Enschede, Netherlands

${ }^{2}$ Digital Life, Amsterdam University of Applied Sciences, Amsterdam, Netherlands

${ }^{3}$ Saxion University of Applied Sciences, Enschede, Netherlands

${ }^{4}$ Leiden Institute of Advanced Computer Science (LIACS), Leiden University, Leiden, Netherlands

${ }^{5}$ University of Twente, Enschede, Netherlands
}

\section{Corresponding Author:}

Christina Jaschinski, PhD

Research Group Technology, Health \& Care

Saxion University of Applied Sciences

M.H. Tromplaan 28

Enschede, $7513 \mathrm{AB}$

Netherlands

Phone: 31657814614

Email: c.jaschinski@saxion.nl

\section{Abstract}

Background: Older adults want to preserve their health and autonomy and stay in their own home environment for as long as possible. This is also of interest to policy makers who try to cope with growing staff shortages and increasing health care expenses. Ambient assisted living (AAL) technologies can support the desire for independence and aging in place. However, the implementation of these technologies is much slower than expected. This has been attributed to the lack of focus on user acceptance and user needs.

Objective: The aim of this study is to develop a theoretically grounded understanding of the acceptance of AAL technologies among older adults and to compare the relative importance of different acceptance factors.

Methods: A conceptual model of AAL acceptance was developed using the theory of planned behavior as a theoretical starting point. A web-based survey of 1296 older adults was conducted in the Netherlands to validate the theoretical model. Structural equation modeling was used to analyze the hypothesized relationships.

Results: Our conceptual model showed a good fit with the observed data (root mean square error of approximation 0.04; standardized root mean square residual 0.06; comparative fit index 0.93; Tucker-Lewis index 0.92) and explained 69\% of the variance in intention to use. All but 2 of the hypothesized paths were significant at the $P<.001$ level. Overall, older adults were relatively open to the idea of using AAL technologies in the future (mean 3.34, SD 0.73).

Conclusions: This study contributes to a more user-centered and theoretically grounded discourse in AAL research. Understanding the underlying behavioral, normative, and control beliefs that contribute to the decision to use or reject AAL technologies helps developers to make informed design decisions based on users' needs and concerns. These insights on acceptance factors can be valuable for the broader field of eHealth development and implementation.

(J Med Internet Res 2021;23(3):e22613) doi: 10.2196/22613

\section{KEYWORDS}

ambient assisted living; assistive technology; healthy aging; technology adoption; theory of planned behavior; structural equation modeling 


\section{Introduction}

\section{Background}

Demographic predictions show a growing number of people at risk for age-related chronic diseases and with a potential need for long-term care. At the same time, there is a growing shortage of caregivers. With the pressing demand for care, the workload for formal and informal caregivers is steadily increasing, negatively affecting their physical and mental well-being [1,2]. These developments put the sustainability of our current health care system at risk [3].

To address these challenges, European care reforms have induced a shift from institutionalized care to more care at home and aging in place. Similarly, the European Union (EU) has embraced an active aging policy strategy that emphasizes good health, security, and participation [4,5]. State-of-the-art assistive technologies, also known as ambient assisted living (AAL) technologies, are viewed as a vital contributor to this strategy.

\section{Ambient Assisted Living}

The term AAL has been introduced by the EU to describe the use of a new generation of information and communication technology (ICT)-based assistive technologies that provide holistic support to older adults in managing their health, remaining independent, and staying involved with their community. AAL technologies are also directed at caregivers to relieve some of their burden and support them in the coordination and management of care tasks [6,7].

AAL builds on the classic principles of ambient intelligence (embedded, context-aware, personalized, adaptive, and anticipatory) [8] to create supportive environments for older adults and their caregivers. AAL is an umbrella term for a range of state-of-the-art technologies such as smart home technology, mobile and wearable technology, and assistive robotics [9]. We previously defined AAL as follows [7]:

\section{State-of-the-art ICT-based solutions that build on the principles of ambient intelligence to create intelligent environments that provide all-encompassing, non-invasive, and pro-active support to older adults and have the ultimate goal to maintain their independence, enhance their overall quality of life, and support their caregivers.}

Application areas are broad and include, for example, health monitoring, activity monitoring, medication management, fall detection, reminder and planning systems, interactive games and storytelling, care management, social companion robots, and ambient awareness systems.

Although there are high hopes for AAL technologies to solve the challenges of the aging population, different systematic reviews conclude that the technology readiness level of these applications is still low and that most applications have not yet matured into the implementation phase. In addition, scientific evidence for the effectiveness of these technologies is weak and efficiency outcomes are almost nonexistent [6,10,11]. Furthermore, research in the AAL area is still predominately technology oriented [6,12], and there is little theoretical understanding of the user's perspective $[11,13]$. Hence, there is a need for further research on user acceptance.

\section{The Importance of User Acceptance}

User acceptance is key to the successful adoption and diffusion of new technologies. Indeed, several researchers have concluded that understanding user acceptance and incorporating user needs is essential to the successful digitization of the health care sector [14-18]. In the context of AAL, the slow deployment of AAL systems has been attributed to the lack of user acceptance and missing focus on user needs [9,13,19]. Loss of privacy [20-22] and the fear of substituting face-to-face interaction [23-26] are examples of acceptance barriers found in previous research. This is not surprising considering the pervasiveness of these technologies [27]. These applications are designed to be placed in personal environments or directly on the body, collect and store sensitive data, influence behavior and habits, and take over tasks that are usually carried out by the older adults themselves or a human caregiver.

The insufficient understanding of users' needs is also reflected in ageist stereotypes, which are still common in this field [28-30]. These studies portray older adults as a homogeneous group that is frail and lonely and has low technology literacy. To combat these stereotypes, researchers need to adopt a more user-centered mindset and develop a deeper understanding of the user's point of view.

Although the number of studies on user acceptance and user needs has slowly increased over the last couple of years, most research still lacks a solid theoretical foundation to explain and underpin their results [11]. This is also confirmed by Blackman et al [31], who concluded that AAL research is rich in data but poor in theory. A solid theoretical foundation is crucial for understanding the underlying social, psychological, and behavioral mechanisms of the acceptance process. A related concern is the lack of large-scale quantitative research on user acceptance in this area $[11,13]$. More quantitative approaches are needed to understand the relative importance of acceptance factors, identify their underlying relationships, and make statistically grounded and externally valid inferences about their influence on the acceptance process. Developing a stronger theoretical and statistically grounded understanding of user acceptance in AAL research will improve AAL conceptualization and development. At the same time, it will increase the likelihood of future acceptance by intended users.

\section{The Conceptual Model of AAL Acceptance}

Technology acceptance occurs over time and consists of different stages [32-36]. Owing to the overall low maturity of AAL technologies, it was decided to focus on early user acceptance, meaning the factors that contribute to the initial intention to use or reject AAL technology in the future.

Over the years, several theories and models have been developed to explain technology acceptance, including the technology acceptance model (TAM) [37,38], the unified theory of acceptance and use of technology (UTAUT) [39], and the theory of planned behavior (TPB) [40]. Although TAM and UTAUT are popular choices in the field of eHealth [18], we chose TPB as a theoretical foundation for several reasons. First, TPB is a 
well-known and validated psychological theory to understand and explain human behavior, including technology acceptance [41-44] and health-related behaviors [45,46]. It has also been applied to understand the adoption of assistive devices [47] and eHealth applications [48]. In contrast, UTAUT is an eclectic model that lacks a strong theoretical foundation [49]. Second, TPB provides an ideal basis for understanding early user acceptance by specifically focusing on the attitudinal, social, and normative belief structure that leads to the intention to use a technology. These insights are very informative for further development and implementation of AAL. In contrast, TAM's predominant focus on usefulness and ease of use provides little valuable insights for the design and implementation of new technologies [50]. Third, TPB is explicitly open to the inclusion of more variables [40] and therefore forms a good starting point for developing a new model of AAL acceptance.

Intention is a central construct in TPB and viewed as an immediate determinant of actual behavior. Intention is defined as an "indication of a person's readiness to perform a given behavior." According to TPB, intention is determined by 3 variables: attitude toward the behavior, subjective norm, and perceived behavioral control. Attitude is defined as "the degree to which performance of the behavior is positively or negatively valued." Subjective norm is defined as the "perceived social pressure to engage or not to engage in a behavior." Perceived behavioral control can be described as "people's perceptions of their ability to perform a given behavior." Following an expectancy value approach, in TPB, attitude is determined by a set of behavioral beliefs about the outcome of a given behavior, weighted by the evaluation of that outcome. Subjective norm is determined by a set of normative beliefs concerning the expectations of important referents, weighted by the motivation to comply. Finally, perceived behavioral control is determined by several control beliefs, weighted by its perceived power $[40,51,52]$.
In line with TPB, intention to use $A A L$ is proposed as the key dependent variable in our conceptual model, with attitude toward using AAL, social norm, and perceived behavioral control as direct ascendants (Figure 1). Personal norm was added as an additional predictor of intention, thereby answering to the appeal of previous researchers to consider different normative mechanisms for TPB $[45,53]$. We define personal norm as "people's self-based standards or expectations for AAL use that flow from one's internalized values," thereby referring to Schwartz [54]. The construct was operationalized in terms of self-identity, drawing on the work of Lee et al [55] and Sparks and Shepherd [56].

For the conceptual model, the underlying behavioral, normative, and control belief structures were decomposed into specific multidimensional belief constructs, as suggested by Taylor and Todd [43]. The advantage of this approach is that it emphasizes the relevant beliefs antecedents for AAL acceptance and, consequently, provides more directive insights for the design of AAL technologies [43]. We drew on earlier user research in the field [23,57-59] and our own qualitative user studies [60,61] to select the relevant underlying beliefs. This resulted in safety, independent living, and relief of family burden as positive belief antecedents for attitude and loss of privacy and loss of human touch as negative belief antecedents. Caregiver influence was proposed as a positive antecedent of social norm, whereas social stigma was proposed as a negative antecedent. Personal norm was hypothesized to be positively influenced by one's personal innovativeness, whereas human touch norm and privacy norm were suggested as negative antecedents. Finally, perceived behavioral control was hypothesized to be positively influenced by self-efficacy, reliability, and level of user control and negatively influenced by financial cost. Multimedia Appendix 1 displays an overview of the underlying belief constructs and their definitions. 
Figure 1. Conceptual model of ambient assisted living acceptance.

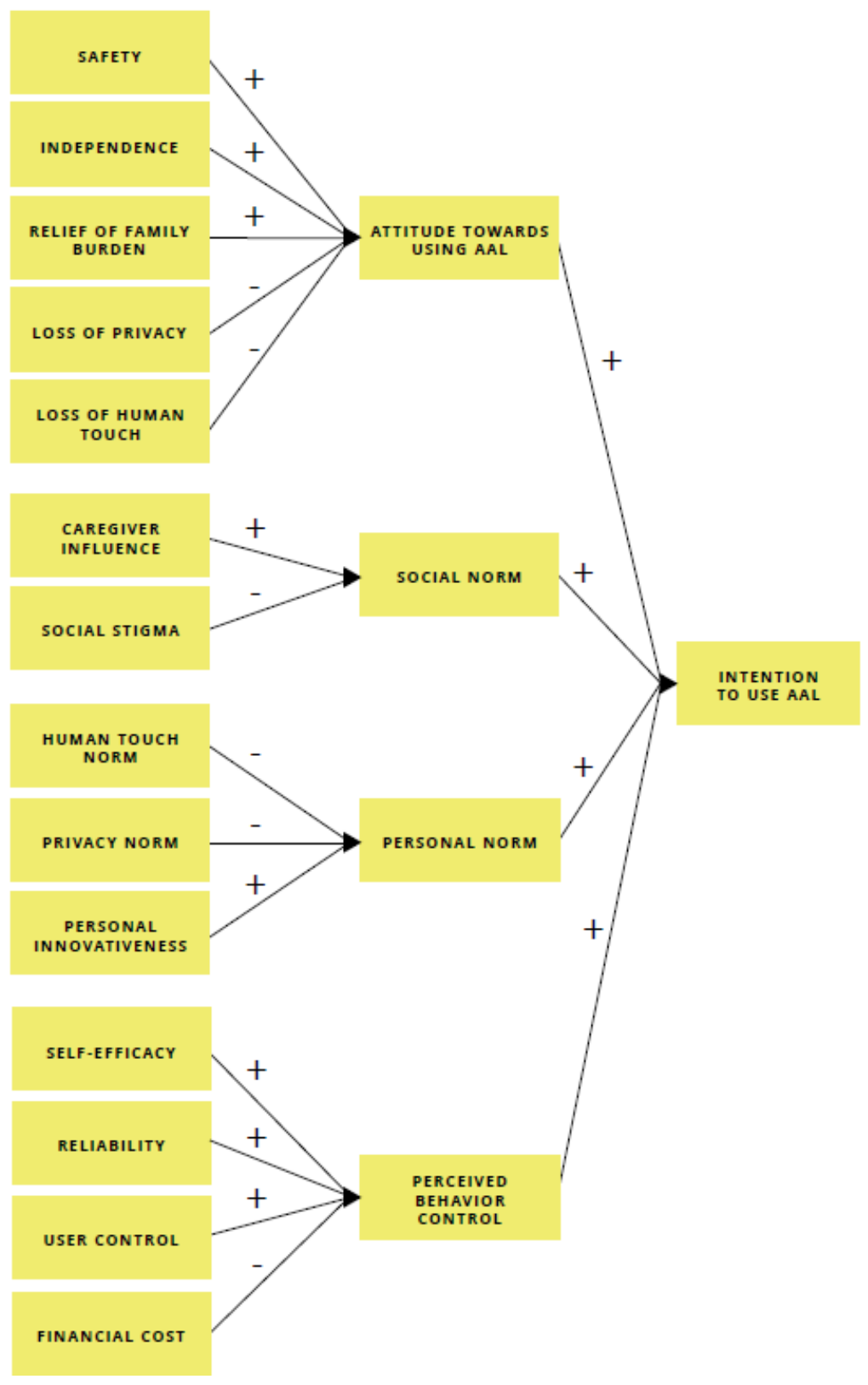

\section{Methods}

\section{Overview}

A web-based survey of older adults was conducted in the Netherlands to validate the conceptual model. A Dutch ISO (International Organization for Standardization)-certified research agency was hired to distribute the survey. The agency is an expert in web-based fieldwork and manages a panel of 110,000 members with diverse sociodemographic backgrounds.

\section{Participants}

Older adults aged between 55 and 85 years were specified as the target population to include older adults with different living and work situations, different perceptions of health and quality of life, different support needs, and different levels of technology experience. Our aim is to adequately represent this highly heterogeneous target group $[62,63]$. The lower boundary of the age requirement was set at 55 years to include the perspective of the future generation of older adults. Predefined age quotas were used to obtain a representative sample.

Upon invitation, 2113 older adults participated in the survey. Of these participants, 679 participants did not complete the survey, most of whom stopped immediately after the introduction page. Another 138 participants were removed from the sample because of: incomplete response patterns, exceptionally short response times, straight lining, and insufficient understanding of the presented AAL material. This led to a response rate of $61.33 \%$ (1296/2113) and a total of 1296 cases for further analysis. The final sample was representative of the older Dutch adult population in terms of age (55-64 years: $\mathrm{n}=555,42.82 \%$; $65-74$ years: $\mathrm{n}=497,38.35 \%$; $75-85$ years: $\mathrm{n}=244,18.83 \%$ ) and gender (male: $\mathrm{n}=637,49.15 \%$; female: $\mathrm{n}=659,50.85 \%)$ [64]. Most of the participants $(\mathrm{n}=1227,94.68 \%)$ had no user experience with AAL applications. All other sample characteristics are presented in Table 1. 
Table 1. Sample characteristics $(\mathrm{N}=1296)$.

\begin{tabular}{|c|c|}
\hline Variables & Values, $\mathrm{n}(\%)$ \\
\hline \multicolumn{2}{|l|}{ Living situation } \\
\hline Alone & $384(29.63)$ \\
\hline With (partner or family or friend) & $912(70.37)$ \\
\hline \multicolumn{2}{|l|}{ Education } \\
\hline Low & $474(36.57)$ \\
\hline Intermediate & $439(33.87)$ \\
\hline Tertiary & $383(29.55)$ \\
\hline \multicolumn{2}{|l|}{ Work situation } \\
\hline Working & $332(25.61)$ \\
\hline Not working & $960(74.07)$ \\
\hline \multicolumn{2}{|l|}{ Self-rated health } \\
\hline Excellent & $88(6.79)$ \\
\hline Very good & $245(18.90)$ \\
\hline Good & $548(42.28)$ \\
\hline Fair & $345(26.62)$ \\
\hline Poor & $70(5.40)$ \\
\hline \multicolumn{2}{|l|}{ Self-rated quality of life } \\
\hline Excellent & $115(8.87)$ \\
\hline Very good & $335(25.85)$ \\
\hline Good & $574(44.29)$ \\
\hline Fair & $248(19.14)$ \\
\hline Poor & $24(1.85)$ \\
\hline \multicolumn{2}{|l|}{ Current support need ${ }^{a}$} \\
\hline No support & $1073(82.79)$ \\
\hline Domestic tasks & $166(12.81)$ \\
\hline Psychosocial support & $88(6.79)$ \\
\hline Personal care & $45(3.47)$ \\
\hline Medical care & $30(2.31)$ \\
\hline \multicolumn{2}{|l|}{ Support provider ${ }^{\mathrm{a}, \mathrm{b}}$} \\
\hline Partner & $95(42.60)$ \\
\hline Child & $62(27.80)$ \\
\hline Family & $13(5.83)$ \\
\hline Friend & $21(9.42)$ \\
\hline Neighbor & $13(5.83)$ \\
\hline Professional & $117(52.47)$ \\
\hline \multicolumn{2}{|l|}{ Expected support need } \\
\hline Highly unlikely & $150(11.57)$ \\
\hline Less likely than others & $186(14.35)$ \\
\hline Equally likely than others & $577(44.52)$ \\
\hline More likely than for others & $114(8.80)$ \\
\hline Highly likely & $90(6.94)$ \\
\hline
\end{tabular}




\begin{tabular}{ll}
\hline Variables & Values, $\mathrm{n}(\%)$ \\
\hline Don't know & $179(13.81)$ \\
\hline
\end{tabular}

${ }^{\mathrm{a}}$ Multiple answers were allowed.

${ }^{\mathrm{b}}$ Of those who reported to receive support $(\mathrm{n}=223)$.

\section{Survey Materials and Procedure}

Participants were presented with a short (2.25 minutes) video animation that explained the concept of AAL [65]. Previous research has shown that animated content with spoken text works well to communicate complex health-related information [66]. For this video animation, a scenario was narrated with the persona Ben, an older adult, and his daughter and informal caregiver, Sophie. Personas and user scenarios are tools that are frequently used in participatory design activities to translate abstract ideas about the user into something more tangible [67]. Three example applications were included in the scenario: (1) smart home technology for activity monitoring and fall detection, (2) a reminder system for appointments and medications, and (3) a social service robot and a social companion robot. In addition to the video animation, participants viewed photos of market-ready AAL products: (1) Sensara activity monitoring [68], (2) Dayclocks reminder application [69], and (3) Zora, a social companion robot [70]. The photos contained a short description of the main features of the product. Two control questions were included to test the understanding of the presented material ("The video/pictures about AAL technology was/were clear to me"). Participants were also asked about their previous knowledge and experience with AAL technology.

After exposure to the video and photos, the participants were directed to the remaining items of the AAL acceptance survey. The survey concluded with questions about the sociodemographic background and participants' self-rated subjective health and overall quality of life, received level of care, and anticipated need for care in the future.

\section{Measurements}

Although some measurements were derived from validated scales, because of the lack of quantitative research in the field, a large part of the measurement was newly developed following the procedure described by DeVellis [71]. Topics from AAL literature and our qualitative user studies $[60,61]$ were used as a starting point to create the initial pool of items. To test and improve the psychometric properties of the newly developed measurements and the overall survey structure, several pretests were conducted. First, the initial pool of items was evaluated for content validity, clarity, and redundancy with 4 senior researchers with expertise in AAL and psychometrics. After this first pretest, some items were removed and the others were rephrased. In the second pretest, the complete web-based survey instrument was presented to 3 older adults to evaluate the overall format (layout, structure, and length), test their ability to navigate through the web-based environment, and evaluate their comprehension of the survey items. Following the guidelines described by Willis [72], we conducted cognitive interviews using a combination of think-aloud and verbal probing techniques, while participants clicked through the survey. As a result, several problem areas were identified and the survey was adjusted accordingly.

We used a 5-point Likert scale as a response scale (1=strongly disagree; $5=$ strongly agree). For the attitude items, a 5-point semantic differential scale was used. Don't know was included as a response option as AAL is a fairly new concept, and we suspected that some participants would not have a strong enough tendency to formulate an opinion [73]. The don't know option was treated as missing values. Full information maximum likelihood (FIML) was used to deal with the missing values. FIML is considered a robust and state-of-the-art approach to handle missing data and is widely recommended in the methodological literature [74-77]. Table 2 gives a concise overview of the operationalization of the key variables included in the survey instrument. Multimedia Appendix 2 $[43,44,47,55,56,78-90]$ shows the final list of items after validation. 
Table 2. Measurements.

\begin{tabular}{|c|c|c|}
\hline Variable name & Number of items in the survey & Example item \\
\hline Intention to use $\mathrm{AAL}^{\mathrm{a}}$ & 4 & In the future, I intend to use AAL technology \\
\hline Attitude toward using AAL & 6 & I (like/dislike) the idea of using AAL technology \\
\hline Social norm & 3 & $\begin{array}{l}\text { Most people whose opinion I value, would think positively about my use } \\
\text { of AAL technology }\end{array}$ \\
\hline Personal norm & 3 & I view myself as a user of technology for my health and well-being \\
\hline Perceived behavioral control & 4 & Using AAL technology is entirely in my control \\
\hline Safety & 6 & If I use AAL technology, I will feel safer in my home \\
\hline Independence & 4 & If I use AAL technology, I can do things independently \\
\hline Relief of family burden & 6 & My use of AAL technology will give my family members peace of mind \\
\hline Loss of privacy & 6 & $\begin{array}{l}\text { If I use AAL technology, I worry that my personal information might be } \\
\text { shared with others without my permission }\end{array}$ \\
\hline Loss of human touch & 6 & If I use AAL technology, I will get less personal attention \\
\hline Caregiver influence & 3 & My caregivers would have a positive view on my use of AAL technology \\
\hline Social stigma & 4 & $\begin{array}{l}\text { If I use AAL technology, I am concerned that the technology will be visible } \\
\text { to others }\end{array}$ \\
\hline Human touch norm & 4 & I prefer personal care over care via AAL technology \\
\hline Privacy norm & 6 & I think I have the right to control my personal information \\
\hline Personal innovativeness & 4 & $\begin{array}{l}\text { If I heard about a new information technology, I would look for ways to } \\
\text { experiment with it }\end{array}$ \\
\hline Self-efficacy & 7 & $\begin{array}{l}\text { If I had problems relating to using AAL technology I know I could work } \\
\text { them out }\end{array}$ \\
\hline User control & 3 & I think that I will feel in control, when using AAL technology \\
\hline Reliability & 4 & I think that AAL technology is reliable \\
\hline Financial cost & 3 & I think that using AAL technology will be expensive \\
\hline
\end{tabular}

${ }^{\mathrm{a}} \mathrm{AAL}$ : ambient assisted living.

\section{Structural Equation Modeling}

We used structural equation modeling (SEM) to validate the conceptual model.

The measurement model was validated in 2 stages. First, a pilot study was conducted among 320 older adults in the Netherlands. The hypothesized relationships between the latent variables and their indicator variables were explored using confirmatory factor analysis. Although this technique is labeled as confirmatory, it was used in an exploratory and iterative manner by paying attention to the posthoc modification indices [91]. By specifying the relationships between the latent variables and their indicator variables a priori, we employed a theory-driven approach rather than a data-driven approach to validate the measurements $[92,93]$. The measurement model was respecified with the main study sample $(\mathrm{N}=1296)$, leading to further refinement of the measurement model.

We used the Lavaan package version $0.5-23$ [94] in $\mathrm{R}$ version 3.4.3 [95] to perform the analysis. Maximum likelihood estimation with FIML for missing data was used because the data were approximately normally distributed. The original measurement model proposed 19 distinct latent factors and 86 indicator variables. Indicators with poor standardized factor loading $(<0.50)$ and low squared multiple correlation $(\mathrm{SMC}<0.40)$ were removed. To further evaluate the convergent validity of the measurement model, we assessed the McDonald hierarchical omega [96], Cronbach alpha [97], and the average variance extracted (AVE) for each latent variable. The threshold for the former 2 measurements was 0.70 , and the recommended AVE value threshold was 0.50 . Discriminant validity was examined using the heterotrait-monotrait (HTMT) ratio. If the HTMT value is $<0.90$, discriminant validity is established [98]. After validating the measurement model, the structural equation model was tested.

\section{Results}

\section{Measurement Model}

The fit measures of the original model were less than aspiration values. After the inspection of factor loadings and SMC values, several indicators were iteratively removed. This included the latent variable user control, as 2 of the 3 indicators loaded poorly on the latent construct. A minimum of 3 indicators are required to represent the latent variable [99]. The indicators of the latent variable privacy norm had low or just acceptable SMC values. As the variable showed relatively weak psychometric properties across the 2 independent samples, privacy norm was removed 
from the measurement model. One indicator (PSN03) with an SMC value less than the aspiration value was not excluded to meet the requirement of the 3 indicators to represent the latent variable. Another indicator less than the aspiration value (PI02) was included because it originated in a validated scale [78]. Upon inspection of the posthoc modification indexes, suggested residual correlations between the following indicator pairs were added: PSN03 and PI02, ATT02 and ATT03, ATT04 and ATT05, LP03 and LP05, LP03 and LP06, LP05 and LP06, and FB03 and FB05. After calculating the hierarchical omega, Cronbach alpha, and AVE values, it was decided to remove the latent variable social stigma from the measurement model because of a low AVE value (AVE=0.47) and overall weak psychometric properties across the 2 samples. Finally, HTMT values indicated that safety and independence should be considered as a single latent variable called safe and independent living.
The final measurement model consisted of 15 latent factors, 63 indicators, and 7 added residual correlations. The model showed acceptable-to-good fit for all fit measures (root mean square error of approximation [RMSEA] $=0.04$; standardized root mean square residual $[\mathrm{SRMR}]=0.05 ;$ comparative fit index $[\mathrm{CFI}]=0.93$; and Tucker Lewis index $[\mathrm{TLI}]=0.92$ ). Multimedia Appendix 3 displays the final list of indicators with intercept (FIML mean), indicator mean (values with listwise deletion), SD (values with listwise deletion), factor loadings, SMC, hierarchical omega, Cronbach alpha, and AVE.

\section{Descriptives}

The indicator scores from the final measurement model were pooled into a composite score for each latent variable. Table 3 shows an overview of the composite mean, $\mathrm{SD}$, and range for each latent variable.

Table 3. Composite mean and SD per latent variable. ${ }^{\mathrm{a}}$

\begin{tabular}{llll}
\hline Latent variable & Mean (SD) & Minimum & Maximum \\
\hline Intention to use AAL & $3.34(0.73)$ & 1 & 5 \\
Attitude toward using AAL & $3.73(0.78)$ & 1 & 5 \\
Social norm & $3.67(0.57)$ & 1 & 5 \\
Personal norm & $3.42(0.75)$ & 1 & 5 \\
Perceived behavioral control & $3.32(0.71)$ & 1 & 5 \\
Safe and independent living & $3.92(0.52)$ & 1 & 5 \\
Relief of family burden & $3.67(0.65)$ & 1 & 5 \\
Loss of privacy & $3.14(0.87)$ & 1 & 5 \\
Loss of human touch & $3.13(0.83)$ & 1 & 5 \\
Caregiver influence & $3.73(0.56)$ & 1 & 5 \\
Human touch norm & $3.97(0.67)$ & 1 & 5 \\
Personal innovativeness & $3.19(0.78)$ & 1 & 5 \\
Self-efficacy & $3.79(0.60)$ & 1 & 5 \\
Reliability & $3.26(0.59)$ & 1 & 5 \\
Financial cost & $3.81(0.68)$ & 1 & 5 \\
\hline
\end{tabular}

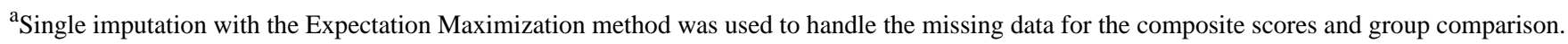

${ }^{\mathrm{b}} \mathrm{AAL}$ : ambient assisted living.

The overall intention to use AAL technology was moderately high in the sample (mean 3.34, SD 0.73). This means that, in general, older adults were relatively open to the idea of using AAL technologies in the future. Regarding the 3 age quotas, there was no significant difference in their use intention $\left(\mathrm{F}_{2,1293}=2.89 ; P=.06\right)$. Similarly, we found no significant differences across different levels of subjective health $\left(\mathrm{F}_{4,1291}=0.60 ; P=.66\right)$ and expected support needs $\left(\mathrm{F}_{4,1112}=0.52\right.$; $P=$.72).

\section{Structural Equation Model}

The hypothesized structural equation model showed good overall fit with the observed data: RMSEA $=0.04, \mathrm{SRMR}=0.06$, $\mathrm{CFI}=0.93$, and TLI $=0.92$. The model accounted for $69 \%$ of the variance in the intention to use $\operatorname{AAL}\left(R^{2}=0.69\right)$. All but 2 of the hypothesized paths had significant standardized path coefficients at the $P<.001$ level.

Attitude toward using AAL, social norm, personal norm, and perceived behavior control significantly affected the intention to use AAL. Attitude was the most important influencer of intention $(\beta=.53)$. Attitude toward using AAL was affected by older adults' expectations about safe and independent living $(\beta=.51)$, relief of family burden $(\beta=.12)$, loss of privacy $(\beta=-.19)$, and loss of human touch $(\beta=-.25)$. Together, these variables explained $71 \%$ of the variance in attitude $\left(R^{2}=0.71\right)$. Social norm was strongly affected by caregiver influence $(\beta=.97)$. Caregiver influence predicted $94 \%$ of the variance in social norm. The hypothesized influence of human touch norm 
on personal norm was not significant $(P=.39)$, and personal innovativeness therefore remained to be the only significant predictor of personal norm $(\beta=.81)$. Personal innovativeness explained $67 \%$ of the variance in personal norm. Self-efficacy $(\beta=.81)$ and financial cost $(\beta=-.12)$ remained to be the 2

Figure 2. Structural equation model. Values adjacent to the single-headed arrows represent the standardized regression coefficients $(P<.001)$. The dotted lines represent the nonsignificant paths. Values above the variable rectangles represent the variance explained in the latent variables.

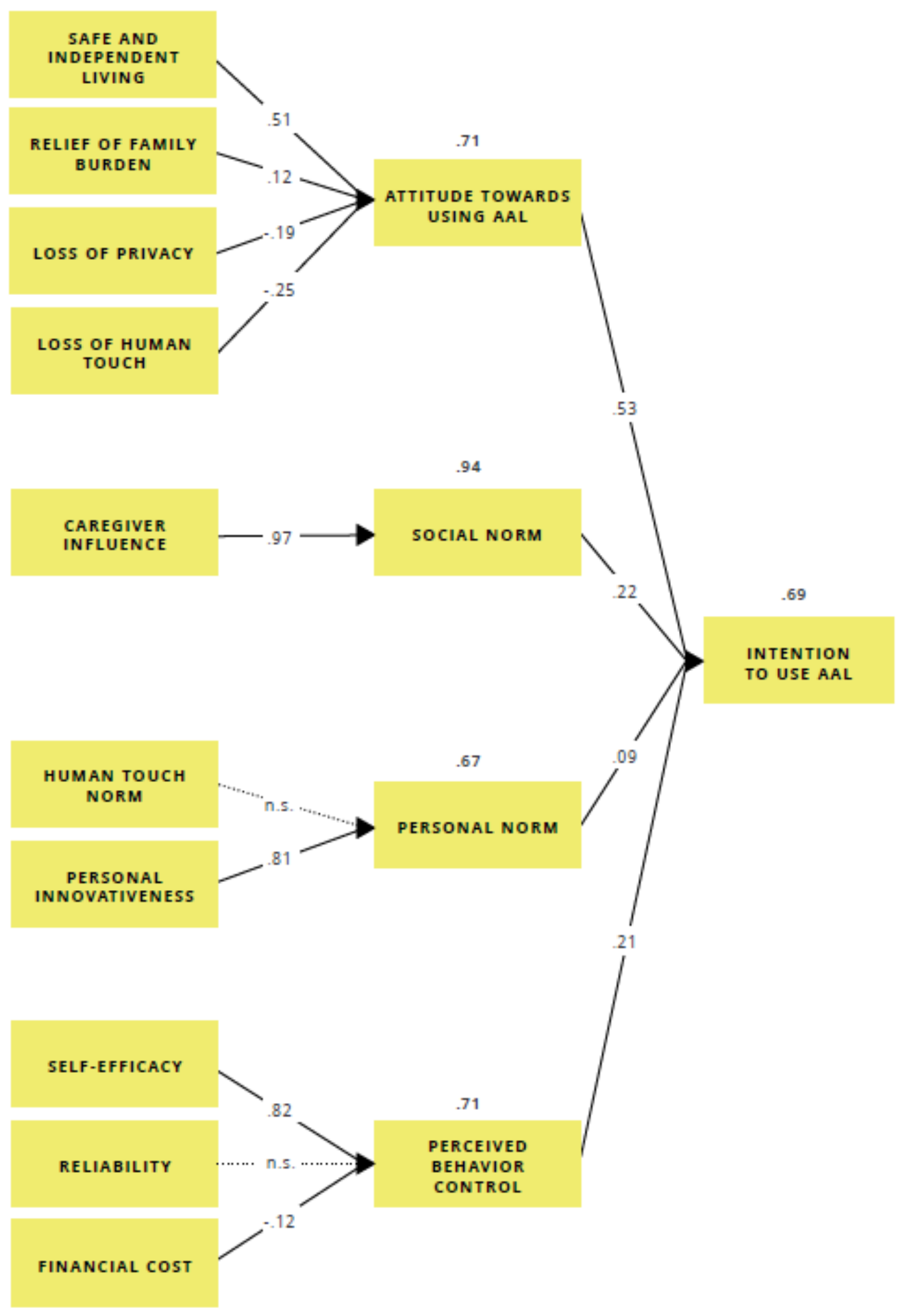

predictors of perceived behavior control. Together, these variables explained $71 \%$ of the variance in the perceived behavior control. The expected influence of reliability was not significant $(P=.68$; Figure 2$)$. 


\section{Discussion}

\section{Principal Findings}

The aim of this study is to develop a statistically grounded understanding of the acceptance of AAL technology among older adults in the Netherlands. Specifically, this study aimed to compare the relative importance of different acceptance factors, their underlying relationships, and their explanatory power for the intention to use AAL technologies in the future.

The results of the web-based acceptance survey showed that the proposed model of AAL acceptance showed a good model fit for the observed data and explained $69 \%$ of the variance in intention to use. All hypothesized paths were significant, except for the path between human touch norm and personal norm and the path between reliability and perceived behavior control Therefore, it can be concluded that our established theoretical model provides a valuable framework for understanding and explaining older adults' acceptance in the early acceptance stage.

The overall intention to use AAL technology was moderately positive. This means that older adults are relatively open to the idea of using AAL technologies in the future. We found no difference in intention to use between age groups, people with different subjective health ratings, and different expected support needs. Although this might be somewhat surprising, this is in line with findings from Ziefle and Röcker [100], who found that age and subjective health status did not influence the willingness to use AAL technologies.

As expected, the intention to use AAL was predicted by attitude toward using AAL, social norm, personal norm, and perceived behavior control. Attitude was the most important predictor, followed by social norm and perceived behavior control. The results showed only a weak influence on personal norm. Ajzen [40] argues that "the relative importance of attitude, subjective norm, and perceived behavioral control in the prediction of intention is expected to vary across behaviors and situations." From the results, we can conclude that in an early acceptance stage, in which people have no or limited experience with AAL technologies, the overall attitude toward using AAL is the most important influencer of intention to use. On the other hand, self-based standards and expectations regarding AAL use are only minor influencers of older adults' intention to use.

Safe and independent living was the most important positive influencer of attitude, which in turn influenced intention to use. This is in line with previous AAL research $[57,59,101]$ and our own qualitative user studies [60,61]. Older adults regarded the increased feeling of safety and the opportunity of independent living as a major advantage of AAL. We also found empirical evidence that promises of safety and autonomy are a valid trade-off for concerns about personal interaction and privacy, as suggested by earlier research [58,102]. Nevertheless, in line with previous studies [20,21,23-26], both concerns still substantially contributed to a negative attitude toward using AAL and should be considered when developing AAL applications. Earlier studies $[58,101,103]$ suggested that older adults perceive AAL technologies as good tools for reducing the overall burden on caregivers. This was confirmed by the results of the AAL acceptance survey.

Previous research has suggested that the influence of caregivers, especially informal family caregivers, is important for the acceptance of AAL technologies [104-106]. Although we did not distinguish between formal and informal caregiver influence, the findings of the AAL acceptance survey indeed identified caregivers as crucial social referents for building social norm. Social norm, in turn, influenced use intentions. For future research, it would be interesting to explicitly distinguish between formal and informal caregiver influence.

In line with our qualitative user studies [60,61], older adults' general willingness to try out new information technology positively contributed to their overall personal norm. However, the effect of personal norm on intention to use AAL was weak in the current sample. In contrast to our expectations, human touch norm had no significant influence on personal norm. An explanation for this finding may be that older adults preferred human care over care via AAL technology but could still identify as users of AAL.

Self-efficacy is a concept derived from social cognitive theory and is an essential determinant of human motivation and behavior [107,108]. Following previous research [57], it was hypothesized that self-efficacy would positively affect use intention via perceived behavior control. This hypothesized relationship was confirmed through the results of the AAL acceptance survey. Moreover, in line with previous research [57,101], expectations about high financial cost negatively contributed to perceived behavioral control. The hypothesized relationship between perceived behavior control and reliability was not significant. We suspect that with no or limited experience of AAL, users found it difficult to formulate specific and consistent expectations about the expected reliability of AAL. However, we believe that reliability will be considered in a later acceptance stage when users are actively interacting with the technology. Therefore, future research should consider these variables.

\section{Limitations}

As in every study, there were some limitations to be considered. First, by using a web-based survey, we accepted that our sample had a bias toward older adults with internet connection and some technology skills. However, most older adults are active internet users $[109,110]$. Hence, the current sample remains to be largely representative of the older Dutch adult population. Second, participants' responses were based on the provided study material and not on direct interaction with AAL technologies. This could have limited participants' impressions of AAL. However, this fits the phase of early acceptance. In real-life situations, older adults will not necessarily try out a new technological device before forming their initial use intention. Previous research has shown that participants can form attitudes and expectations toward new and unfamiliar technologies without active use experience [32,111-113]. Finally, reaching an acceptable model fit in SEM does not imply that the hypothesized model is the only fitting model. Other equivalent or near-equivalent models may show equal or even better fit [93]. However, at this stage, the AAL field does not 
offer a rich theoretical discourse to inspire alternative models. Moreover, the measurement part of the model was cross-validated across 2 independent samples. In addition, the model was built on a strong and well-established psychological theory (TPB), a literature review, and several qualitative user studies.

\section{Future Research}

To the best of our knowledge, this model is one of the first theory-driven quantitative frameworks for understanding AAL acceptance, which has been validated with a representative sample of the target population. However, this also means that this model is the first approximation to explain AAL acceptance. Further cross-validation and refinement is needed to ensure that this model remains stable and valid across different populations and cultural contexts. The established model focuses on early user acceptance and the initial intention to use AAL. Future research needs to implement longitudinal designs to explore later stages of acceptance when older adults start using the technology in their own home environment and attitudes, user needs, and intentions might change [34,35,114]. This study focused on older adults. Other important stakeholder groups include informal and formal caregivers. They can be primary users of AAL applications [115] and are important in signaling the older adults' need for support and introducing AAL into the home care practice [7]. Hence, future research should further investigate caregivers' perceptions of AAL.

For now, our insights into early acceptance among older adults can shape the further discourse and implementation of AAL.

\section{Conclusions}

For the future success of AAL, it is vital to know if these technologies will fall on fertile ground and will be accepted by the intended users. In other words, will the policy vision of AAL as a solution to healthy and independent aging become reality from the perspective of older adult users? This study shows that Dutch older adults seem receptive to the idea of using AAL technology in the future. Being mindful of the acceptance factors will help developers make more informed design decisions before diffusing applications into the market.

Although the provided model focuses on AAL technologies, our insights on acceptance factors (eg, loss of privacy, loss of human touch, caregiver influence, financial cost) can also be valuable for the broader field of eHealth development and implementation.

\section{Acknowledgments}

The authors would like to thank the participants for taking the time to participate in the survey.

\section{Authors' Contributions}

CJ, SBA, JD, and OP were responsible for the conception and design of the study. CJ managed the data collection. All authors were involved in the statistical analysis and interpretation of the data. CJ, SBA, and OP drafted and critically revised the manuscript. CJ and SBA approved the final manuscript.

\section{Conflicts of Interest}

None declared.

\section{Multimedia Appendix 1}

Definition of the proposed belief constructs.

[PDF File (Adobe PDF File), $401 \mathrm{~KB}-$ Multimedia Appendix 1]

\section{Multimedia Appendix 2}

Refined measurements of the ambient assisted living acceptance survey.

[PDF File (Adobe PDF File), 573 KB-Multimedia Appendix 2]

\section{Multimedia Appendix 3}

Final measurement model intercept, mean, SD, standardized factor loadings, hierarchical omega, Cronbach alpha, and average variance extracted. [PDF File (Adobe PDF File), 572 KB-Multimedia Appendix 3]

\section{References}

1. Hasson H, Arnetz JE. Nursing staff competence, work strain, stress and satisfaction in elderly care: a comparison of home-based care and nursing homes. J Clin Nurs 2008 Feb;17(4):468-481. [doi: 10.1111/j.1365-2702.2006.01803.x] [Medline: 17331093 ]

2. Deeken JF, Taylor KL, Mangan P, Yabroff KR, Ingham JM. Care for the caregivers: a review of self-report instruments developed to measure the burden, needs, and quality of life of informal caregivers. J Pain Symptom Manage 2003 Oct;26(4):922-953 [FREE Full text] [doi: 10.1016/s0885-3924(03)00327-0] [Medline: 14527761] 
3. Colombo F, Llena-Nozal A, Mercier J, Tjadens F. Help Wanted? Providing and Paying for Long-Term Care. OECD Publishing. 2011 May 18. URL: https://www.oecd-ilibrary.org/social-issues-migration-health/help-wanted 9789264097759-en [accessed 2020-07-17]

4. Active Ageing: a Policy Framework. World Health Organization. 2002 Apr. URL: https://www.who.int/ageing/publications/ active ageing/en/ [accessed 2020-07-17]

5. Foster L, Walker A. Active and successful aging: a European policy perspective. Gerontologist 2015 Feb;55(1):83-90 [FREE Full text] [doi: 10.1093/geront/gnu028] [Medline: 24846882]

6. Calvaresi D, Cesarini D, Sernani P, Marinoni M, Dragoni AF, Sturm A. Exploring the ambient assisted living domain: a systematic review. J Ambient Intell Human Comput 2016 May 4;8(2):239-257. [doi: 10.1007/s12652-016-0374-3]

7. Jaschinski C, Ben Allouch S. Listening to the ones who care: exploring the perceptions of informal caregivers towards ambient assisted living applications. J Ambient Intell Human Comput 2018 May 25;10(2):761-778. [doi:

$10.1007 / \mathrm{s} 12652-018-0856-6]$

8. Aarts EHL, Marzano S. The New Everyday: Views on Ambient Intelligence. Rotterdam: 010 Publishers; 2003.

9. Rashidi P, Mihailidis A. A survey on ambient-assisted living tools for older adults. IEEE J Biomed Health Inform 2013 May;17(3):579-590. [doi: 10.1109/jbhi.2012.2234129] [Medline: 24592460]

10. Krick T, Huter K, Domhoff D, Schmidt A, Rothgang H, Wolf-Ostermann K. Digital technology and nursing care: a scoping review on acceptance, effectiveness and efficiency studies of informal and formal care technologies. BMC Health Serv Res 2019 Jun 20;19(1):400 [FREE Full text] [doi: 10.1186/s12913-019-4238-3] [Medline: 31221133]

11. Liu L, Stroulia E, Nikolaidis I, Miguel-Cruz A, Rios Rincon A. Smart homes and home health monitoring technologies for older adults: A systematic review. Int J Med Inform 2016 Jul;91:44-59. [doi: 10.1016/j.ijmedinf.2016.04.007] [Medline: 27185508]

12. Queirós A, Silva A, Alvarelhão J, Rocha NP, Teixeira A. Usability, accessibility and ambient-assisted living: a systematic literature review. Univ Access Inf Soc 2013 Oct 5;14(1):57-66. [doi: 10.1007/s10209-013-0328-x]

13. Peek STM, Wouters EJM, van HJ, Luijkx KG, Boeije HR, Vrijhoef HJ. Factors influencing acceptance of technology for aging in place: a systematic review. Int J Med Inform 2014 Apr;83(4):235-248 [FREE Full text] [doi: 10.1016/j.ijmedinf.2014.01.004] [Medline: 24529817]

14. McGinn CA, Grenier S, Duplantie J, Shaw N, Sicotte C, Mathieu L, et al. Comparison of user groups' perspectives of barriers and facilitators to implementing electronic health records: a systematic review. BMC Med 2011 Apr 28;9:46 [FREE Full text] [doi: 10.1186/1741-7015-9-46] [Medline: 21524315]

15. Cresswell KM, Bates DW, Sheikh A. Ten key considerations for the successful optimization of large-scale health information technology. J Am Med Inform Assoc 2016 Apr 23. [doi: 10.1093/jamia/ocw037] [Medline: 27107441]

16. Cresswell K, Morrison Z, Crowe S, Robertson A, Sheikh A. Anything but engaged: user involvement in the context of a national electronic health record implementation. Inform Prim Care 2011;19(4):191-206 [FREE Full text] [doi:

10.14236/jhi.v19i4.814] [Medline: 22828574]

17. Yusif S, Hafeez-Baig A, Soar J. e-Health readiness assessment factors and measuring tools: a systematic review. Int J Med Inform 2017 Dec;107:56-64. [doi: 10.1016/j.ijmedinf.2017.08.006] [Medline: 29029692]

18. Harst L, Lantzsch H, Scheibe M. Theories predicting end-user acceptance of telemedicine use: systematic review. J Med

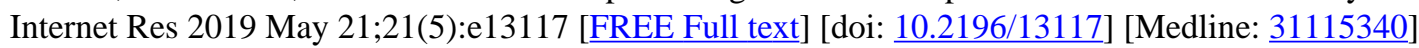

19. Robinson H, MacDonald B, Broadbent E. The Role of Healthcare Robots for Older People at Home: A Review. Int J of Soc Robotics 2014 Jul 3;6(4):575-591. [doi: 10.1007/s12369-014-0242-2]

20. Yusif S, Soar J, Hafeez-Baig A. Older people, assistive technologies, and the barriers to adoption: a systematic review. Int J Med Inform 2016 Dec;94:112-116. [doi: 10.1016/j.ijmedinf.2016.07.004] [Medline: 27573318]

21. Fischer SH, David D, Crotty BH, Dierks M, Safran C. Acceptance and use of health information technology by community-dwelling elders. Int J Med Inform 2014 Sep;83(9):624-635 [FREE Full text] [doi: 10.1016/j.ijmedinf.2014.06.005] [Medline: 24996581]

22. Wilkowska W, Ziefle M. Privacy and data security in E-health: requirements from the user's perspective. Health Informatics J 2012 Sep;18(3):191-201 [FREE Full text] [doi: 10.1177/1460458212442933] [Medline: 23011814]

23. Beer JM, Takayama L. Mobile Remote Presence Systems for Older Adults: Acceptance, Benefits, and Concerns. In: Proceedings of the 6th international conference on Human-robot interaction. New York: ACM; 2011 Presented at: 6th International Conference on Human-Robot Interaction (HRI '11); 2011 March; Lausanne, Switzerland p. 19-26. [doi: $\underline{10.1145 / 1957656.1957665]}$

24. Demiris G, Rantz M, Aud M, Marek K, Tyrer H, Skubic M, et al. Older adults' attitudes towards and perceptions of 'smart home' technologies: a pilot study. Med Inform Internet Med 2004 Jun;29(2):87-94. [doi: 10.1080/14639230410001684387] [Medline: 15370989]

25. Marquis-Faulkes F, McKenna SJ, Gregor P, Newell AF. Scenario-based drama as a tool for investigating user requirements with application to home monitoring for elderly people. In: Proceedings of the 10th International Conference on Human-Computer Interaction. 2003 Presented at: 10th International Conference on Human-Computer Interaction (HCI International); 2003 June 22-27; Crete, Greece p. 512-516. 
26. Kang HG, Mahoney DF, Hoenig H, Hirth VA, Bonato P, Hajjar I, et al. In situ monitoring of health in older adults: technologies and issues. J Am Geriatr Soc 2010 Aug;58(8):1579-1586. [doi: 10.1111/j.1532-5415.2010.02959.x] [Medline: 20646105]

27. Novitzky P, Smeaton AF, Chen C, Irving K, Jacquemard T, O'Brolcháin F, et al. A review of contemporary work on the ethics of ambient assisted living technologies for people with dementia. Sci Eng Ethics 2015 Jun;21(3):707-765. [doi: 10.1007/s11948-014-9552-x] [Medline: 24942810]

28. Fischer B, Peine A, Östlund B. The Importance of User Involvement: A Systematic Review of Involving Older Users in Technology Design. Gerontologist 2020 Sep 15;60(7):e513-e523 [FREE Full text] [doi: 10.1093/geront/gnz163] [Medline: 31773145]

29. Peine A, Rollwagen I, Neven L. The rise of the 'innosumer'-Rethinking older technology users. Technological Forecasting and Social Change 2014 Feb;82:199-214. [doi: 10.1016/j.techfore.2013.06.013]

30. Vines J, Pritchard G, Wright P, Olivier P, Brittain K. An Age-Old Problem: Examining the Discourses of Ageing in HCI and Strategies for Future Research. ACM Trans. Comput.-Hum. Interact 2015 Mar 04;22(1):1-27. [doi: 10.1145/2696867]

31. Blackman S, Matlo C, Bobrovitskiy C, Waldoch A, Fang M, Jackson P, et al. Ambient Assisted Living Technologies for Aging Well: A Scoping Review. Journal of Intelligent Systems 2016;25(1):55-69. [doi: 10.1515/jisys-2014-0136]

32. Karahanna E, Straub DW, Chervany NL. Information Technology Adoption Across Time: A Cross-Sectional Comparison of Pre-Adoption and Post-Adoption Beliefs. MIS Q 1999;23(2):183-213. [doi: 10.2307/249751]

33. Karapanos E, Zimmerman J, Forlizzi J, Martens J. User experience over time: An initial framework. In: Proceedings of the SIGCHI Conference on Human Factors in Computing Systems. New York: ACM; 2009 Presented at: SIGCHI Conference on Human Factors in Computing Systems (CHI '09); 2009 April; Boston, MA, USA p. 729-738. [doi: 10.1145/1518701.1518814]

34. de Graaf MM, Ben Allouch S, van Dijk JAGM. Long-term evaluation of a social robot in real homes. Interaction Studies 2016 Jan;17(3):462-491. [doi: 10.1075/is.17.3.08deg]

35. Chiu TML, Eysenbach G. Stages of use: consideration, initiation, utilization, and outcomes of an internet-mediated intervention. BMC Med Inform Decis Mak 2010;10:73 [FREE Full text] [doi: 10.1186/1472-6947-10-73] [Medline: 21092275]

36. Rogers EM. Diffusion of Innovations. 5th edition. New York: Free Press; 2003.

37. Davis FD, Bagozzi RP, Warshaw PR. User acceptance of computer technology: a comparison of two theoretical models. Manag Sci 1989 Aug;35(8):982-1003. [doi: 10.1287/mnsc.35.8.982]

38. Davis FD. A technology acceptance model for empirically testing new end-user information systems : theory and results. Cambridge: Massachusetts Institute of Technology; 1986. URL: http://hdl.handle.net/1721.1/15192 [accessed 2020-07-17]

39. Venkatesh V, Morris MG, Davis GB, Davis FD. User Acceptance of Information Technology: Toward a Unified View. MIS Quarterly 2003;27(3):425-478. [doi: $10.2307 / 30036540]$

40. Ajzen I. The theory of planned behavior. Organizational Behavior and Human Decision Processes 1991 Dec;50(2):179-211. [doi: 10.1016/0749-5978(91)90020-T]

41. Pavlou PA, Fygenson M. Understanding and Predicting Electronic Commerce Adoption: An Extension of the Theory of Planned Behavior. MIS Quarterly 2006 Mar;30(1):115-143. [doi: 10.2307/25148720]

42. de Graaf MMA, Ben Allouch S, van Dijk JAGM. Why Would I Use This in My Home? A Model of Domestic Social Robot Acceptance. Human-Computer Interaction 2017 Jul 21;34(2):115-173. [doi: 10.1080/07370024.2017.1312406]

43. Taylor S, Todd PA. Understanding information technology usage: A test of competing models. Inf Syst Res 1995;6(2):144-176. [doi: 10.1287/isre.6.2.144]

44. Mathieson K. Predicting user intentions: Comparing the technology acceptance model with the theory of planned behavior. Inf Syst Res 1991;2(3):173-191. [doi: 10.1287/isre.2.3.173]

45. Godin G, Kok G. The theory of planned behavior: a review of its applications to health-related behaviors. Am J Health Promot 1996;11(2):87-98. [doi: 10.4278/0890-1171-11.2.87] [Medline: 10163601]

46. Hackman CL, Knowlden AP. Theory of reasoned action and theory of planned behavior-based dietary interventions in adolescents and young adults: a systematic review. Adolesc Health Med Ther 2014;5:101-114 [FREE Full text] [doi: 10.2147/AHMT.S56207] [Medline: 24966710]

47. Roelands M, Van Oost P, Depoorter A, Buysse A. A social-cognitive model to predict the use of assistive devices for mobility and self-care in elderly people. Gerontologist 2002 Feb;42(1):39-50. [doi: 10.1093/geront/42.1.39] [Medline: $\underline{11815698]}$

48. Herrmann LK, Kim J. The fitness of apps: a theory-based examination of mobile fitness app usage over 5 months. Mhealth 2017;3:2 [FREE Full text] [doi: 10.21037/mhealth.2017.01.03] [Medline: 28293619]

49. Bagozzi RP. The Legacy of the Technology Acceptance Model and a Proposal for a Paradigm Shift. Journal of the Association for Information Systems 2007 Apr;8(4):244-254. [doi: 10.17705/1jais.00122]

50. Benbasat I, Barki H. Quo vadis TAM? Journal of the Association for Information Systems 2007 Apr;8(4):211-218.

51. Ajzen I, Fishbein M. The Influence of Attitudes on Behavior. In: Albarracin D, Johnson BT, Zanna MP, editors. The handbook of attitudes. New Jersey: Lawrence Erlbaum Associates Publishers; 2005:173-221. 
52. Ajzen I. Theory of Planned Behavior Diagram. 2019. URL: https://people.umass.edu/aizen/tpb.diag.html\#null-link [accessed 2020-07-03]

53. Armitage CJ, Conner M. Efficacy of the Theory of Planned Behaviour: a meta-analytic review. Br J Soc Psychol 2001 Dec;40(Pt 4):471-499. [Medline: 11795063]

54. Schwartz SH. Normative Influences on Altruism. Advances in Experimental Social Psychology 1977;10:221-279. [doi: 10.1016/s0065-2601(08)60358-5]

55. Lee Y, Lee J, Lee Z. Social Influence on Technology Acceptance Behaviorlf-Identity Theory Perspective). SIGMIS Database 2006 Sep 19;37(2-3):60-75. [doi: 10.1145/1161345.1161355]

56. Sparks P, Shepherd R. Self-Identity and the Theory of Planned Behavior: Assesing the Role of Identification with Green Consumerism. Social Psychology Quarterly 1992 Dec;55(4):388-399. [doi: 10.2307/2786955]

57. Steele R, Lo A, Secombe C, Wong YK. Elderly persons' perception and acceptance of using wireless sensor networks to assist healthcare. Int J Med Inform 2009 Dec;78(12):788-801. [doi: 10.1016/j.ijmedinf.2009.08.001] [Medline: 19717335]

58. Wild K, Boise L, Lundell J, Foucek A. Unobtrusive in-home monitoring of cognitive and physical health: reactions and perceptions of older adults. J Appl Gerontol 2008;27(2):181-200 [FREE Full text] [doi: 10.1177/0733464807311435] [Medline: 19165352]

59. van Hoof J, Kort HSM, Rutten PGS, Duijnstee MSH. Ageing-in-place with the use of ambient intelligence technology: perspectives of older users. Int J Med Inform 2011 May;80(5):310-331 [FREE Full text] [doi: 10.1016/j.ijmedinf.2011.02.010] [Medline: 21439898]

60. Jaschinski C, Ben Allouch S. An Extended View on Benefits and Barriers of Ambient Assisted Living Solutions. International Journal on Advances in Life Sciences 2015;7(1\&2):40-53.

61. Jaschinski C, Ben Allouch S. Understanding the User's Acceptance of a Sensor-Based Ambient Assisted Living Application. In: Salah AA, Kröse BJA, Cook DJ, editors. Human Behavior Understanding. Lecture Notes in Computer Science, vol 9277. Cham: Springer International Publishing; Nov 2015:13-25. [doi: 10.1007/978-3-319-24195-1 2]

62. Gregor P, Newell AF, Zaijcek M. Designing for Dynamic Diversity: Interfaces for Older People. In: Proceedings of the 5th International ACM Conference on Assistive Technologies. New York: ACM; 2002 Jul Presented at: 5th International ACM Conference on Assistive Technologies (Assets '02); 2002 July; Edinburgh, Scotland p. 151-156. [doi: 10.1145/638249.638277]

63. Grates M, Heming A, Vukoman M, Schabsky P, Sorgalla J. New Perspectives on User Participation in Technology Design Processes: An Interdisciplinary Approach. Gerontologist 2019 Jan 09;59(1):45-57. [doi: 10.1093/geront/gny112] [Medline: $\underline{\text { 30260407] }}$

64. Statistics Netherlands. StatLine - Bevolking; geslacht, leeftijd en burgerlijke staat, 1 januari. 2020. URL: https://opendata. cbs.nl/statline/\#/CBS/nl/dataset/7461bev/table?dl=B875 [accessed 2020-07-17]

65. Jaschinski C. Independent Aging with the Help of Smart Technology. 2018 Apr 26. URL: https://www.youtube.com/ watch?v=TZfy5KW9kOY [accessed 2020-07-17]

66. Meppelink CS, van Weert JCM, Haven CJ, Smit EG. The effectiveness of health animations in audiences with different health literacy levels: an experimental study. J Med Internet Res 2015 Jan 13;17(1):e11 [FREE Full text] [doi: 10.2196/jmir.3979] [Medline: 25586711]

67. Grudin J, Pruitt J. Personas, Participatory Design and Product Development: An Infrastructure for Engagement. In: Proceedings of Participation and Design Conference. 2002 Presented at: Participation and Design Conference (PDC 2002); 2002 June 23-25; Malmo, Sweden p. 144-152. [doi: 10.1145/997078.997089]

68. Sensara. Sensara: Beter weten, beter zorgen. URL: https://sensara.eu/\#start-0 [accessed 2020-06-20]

69. DayClocks International B.V. DayClocks - Dé tablet voor oriëntatie, planning en verbinding. URL: https://www.dayclocks.nl/ [accessed 2020-06-20]

70. Zora Robotics NV. Zorabots. URL: https://www.zorarobotics.be [accessed 2020-06-20]

71. DeVellis R. Scale development:Theory and Applications. Thousand Oaks: SAGE Publications; 2003.

72. Willis GB. Cognitive Interviewing: A Tool for Improving Questionnaire Design. Thousand Oaks: SAGE Publications; 2005.

73. Rubin DB, Stern HS, Vehovar V. Handling Don't Know Survey Responses: The Case of the Slovenian Plebiscite. Journal of the American Statistical Association 1995 Sep;90(431):822-828. [doi: 10.2307/2291315]

74. Baraldi AN, Enders CK. An introduction to modern missing data analyses. J Sch Psychol 2010 Feb;48(1):5-37. [doi: 10.1016/j.jsp.2009.10.001] [Medline: 20006986]

75. Little TD, Jorgensen TD, Lang KM, Moore EWG. On the joys of missing data. J Pediatr Psychol 2014 Mar 08;39(2):151-162. [doi: 10.1093/jpepsy/jst048] [Medline: 23836191]

76. Enders C, Bandalos D. The relative performance of full information maximum likelihood estimation for missing data in structural equation models. Structural Equation Modeling 2001 Jul 1;8(3):430-457. [doi: 10.1207/s15328007sem0803_5]

77. Olinsky A, Chen S, Harlow L. The comparative efficacy of imputation methods for missing data in structural equation modeling. European Journal of Operational Research 2003 Nov;151(1):53-79. [doi: 10.1016/s0377-2217(02)00578-7]

78. Agarwal R, Prasad J. A Conceptual and Operational Definition of Personal Innovativeness in the Domain of Information Technology. Inf Syst Res 1998;9(2):204-215. [doi: 10.1287/isre.9.2.204] 
79. Ben Allouch S, van Dijk JAGM, Peters O. The acceptance of domestic ambient intelligence appliances by prospective users. In: Tokuda H, Beigl M, Friday M, Brush AJB, Tobe Y, editors. Pervasive Computing. Pervasive 2009. Lecture Notes in Computer Science, vol 5538. Berlin, Heidelberg: Springer; 2009. [doi: 10.1007/978-3-642-01516-8 7]

80. Norman P, Bell R. The Theory of Planned Behaviour and exercise: Evidence for the moderating role of past behaviour. Br J Health Psychol 2010 Dec 16;5(3):249-261. [doi: 10.1348/135910700168892]

81. Bédard M, Molloy DW, Squire L, Dubois S, Lever JA, O'Donnell M. The Zarit Burden Interview: a new short version and screening version. Gerontologist 2001 Oct;41(5):652-657. [doi: 10.1093/geront/41.5.652] [Medline: 11574710 ]

82. Boise L, Wild K, Mattek N, Ruhl M, Dodge HH, Kaye J. Willingness of older adults to share data and privacy concerns after exposure to unobtrusive in-home monitoring. Gerontechnology 2013;11(3):428-435 [FREE Full text] [doi: 10.4017/gt.2013.11.3.001.00] [Medline: 23525351]

83. Kirchbuchner F, Grosse-Puppendahl T, Hastall MR, Distler M, Kuijper A. Ambient intelligence from senior citizens' perspectives: understanding privacy concerns, technology acceptance, and expectations. In: Ambient Intelligence. AmI 2015. Lecture Notes in Computer Science. Cham: Springer; 2015. [doi: 10.1007/978-3-319-26005-1_4]

84. Ajzen I. Constructing a theory of planned behavior questionnaire. TPB Questionnaire Construction. URL: http://people. umass.edu/aizen/pdf/tpb.measurement.pdf [accessed 2021-03-03]

85. Dabholkar P. Consumer evaluations of new technology-based self-service options: an investigation of alternative models of service quality. Int J Res Marketing 1996 Feb;13(1):29-51. [doi: 10.1016/0167-8116(95)00027-5]

86. Phang C, Sutanto J, Kankanhalli A, Li Y, Tan B, Teo H. Senior citizens' acceptance of information systems: a study in the context of e-government services. IEEE Trans Eng Manage 2006 Nov;53(4):555-569. [doi: 10.1109/TEM.2006.883710]

87. Larose R. Measuring sustainable broadband adoption: an innovative approach to understanding broadband adoption and use. Int J Commun 2012 Jan:2576-2600 [FREE Full text] [doi: 10.5167/uzh-71046]

88. Meuter ML, Ostrom AL, Bitner MJ, Roundtree R. The influence of technology anxiety on consumer use and experiences with self-service technologies. J Bus Res 2003;56(11):899-906. [doi: 10.1016/s0148-2963(01)00276-4]

89. Mcknight DH, Carter M, Thatcher JB, Clay PF. Trust in a specific technology. ACM Trans Manage Inf Syst 2011 Jun;2(2):1-25. [doi: 10.1145/1985347.1985353]

90. Luarn P, Lin H. Toward an understanding of the behavioral intention to use mobile banking. Comput Human Behav 2005 Nov;21(6):873-891. [doi: 10.1016/j.chb.2004.03.003]

91. Bentler PM. SEM with simplicity and accuracy. J Consum Psychol 2010 Apr;20(2):215-220 [FREE Full text] [doi: 10.1016/j.jcps.2010.03.002] [Medline: 20454589]

92. Jöreskog KG. Testing Structural Equation Models. In: Bollen KA, Long JS, editors. Testing Structural Equation Models. Newbury Park: SAGE Publications; 1993:294-316.

93. Kline RB. Principles and practice of structural equation modeling. New York: Guilford Press; 2016.

94. Rosseel Y. lavaan: An R Package for Structural Equation Modeling. Journal of Statistical Software 2012;48(2):1-36. [doi: 10.18637/jss.v048.i02]

95. R Core Team. R: A language and environment for statistical computing. Vienna, Austria: R Foundation for Statistical Computing URL: https://www.r-project.org [accessed 2020-07-02]

96. McDonald RP, Ho MR. Principles and practice in reporting structural equation analyses. Psychol Methods 2002 Mar;7(1):64-82. [Medline: 11928891]

97. Cronbach LJ. Coefficient alpha and the internal structure of tests. Psychometrika 1951 Sep;16(3):297-334. [doi: 10.1007/BF02310555]

98. Henseler J, Ringle CM, Sarstedt M. A new criterion for assessing discriminant validity in variance-based structural equation modeling. J Acad Mark Sci 2014 Aug 22;43(1):115-135. [doi: 10.1007/s11747-014-0403-8]

99. Hair JF, Black WC, Babin BJ, Anderson RE. Multivariate Data Analysis. Upper Saddle River: Prentice Hall; 2010.

100. Ziefle M, Röcker C. Acceptance of pervasive healthcare systems: A comparison of different implementation concepts. In: Proceedings of the 4th International Conference on Pervasive Computing Technologies for Healthcare. Acceptance of pervasive healthcare systems; 2010 Presented at: 4th International Conference on Pervasive Computing Technologies for Healthcare; 2010 March 22-25; Munich, Germany. [doi: 10.4108/icst.pervasivehealth2010.8915]

101. Sixsmith AJ. An evaluation of an intelligent home monitoring system. J Telemed Telecare 2000;6(2):63-72. [Medline: 10824373]

102. Townsend D, Knoefel F, Goubran R. Privacy versus autonomy: a tradeoff model for smart home monitoring technologies. Annu Int Conf IEEE Eng Med Biol Soc 2011;2011:4749-4752. [doi: 10.1109/IEMBS.2011.6091176] [Medline: 22255399]

103. Rowan J, Mynatt E. Digital Family Portrait Field Trial: Support for Aging in Place. In: Proceedings of the SIGCHI Conference on Human Factors in Computing Systems. New York: ACM; 2005 Presented at: SIGCHI Conference on Human Factors in Computing Systems (CHI '05); 2005 April; Portland, Oregon, USA p. 521-530. [doi: 10.1145/1054972.1055044]

104. Courtney K, Demiris G, Rantz M, Skubic M. Needing smart home technologies: the perspectives of older adults in continuing care retirement communities. Journal of innovation in health informatics 2008 Nov 01;16(3):195-201. [doi: 10.14236/jhi.v16i3.694]

105. Lorenzen-Huber L, Boutain M, Camp LJ, Shankar K, Connelly KH. Privacy, Technology, and Aging: A Proposed Framework. Ageing International 2010 Dec 2;36(2):232-252. [doi: 10.1007/s12126-010-9083-y] 
